\title{
CLAVES DIALÉCTICAS DE LA HERMENÉUTICA GADAMERIANA
}

\section{Cleres Kant}

En este estudio nos proponemos investigar los elementos que constituyen la hermenéutica filosófica como una dialéctica específica, sobre la base de los referentes históricos del quehacer dialéctico con los que confronta su propia concepción del logos como discursividad dialógica. Cuando mencionamos las relaciones que la hermenéutica filosófica mantiene con la dialéctica de la antigüedad clásica o del idealismo alemán, será con la perspectiva de la palabra viva y situada pues el modelo que se nos presenta es el dialógico de inspiración platónica, esto es, una conversación abierta, crítica y virtualmente iluminada.

El diálogo es el lugar común donde se evalúa la multiplicidad de los comportamientos lingüísticos, desde el científico enunciativo hasta el filosófico y el poético. Desde sus comienzos, la obra de Hans-Georg Gadamer (pues de él se trata) se va perfilando en abierta confrontación con el positivismo y el racionalismo, que sólo dan lugar a los hechos y al encadenamiento enunciativo, prácticas científicas que ignoran sus propios prejuicios dogmáticos. No es ignorándolo como el hermeneuta trasciende el dominio de la ciencia, marca sus límites al señalar que la servidumbre a los hechos implica una valorización que no es del orden científico.

A la imagen de una episteme progresiva, lineal, sostenida por logros metódicos de consecuencias evidentes y necesarias, la hermenéutica filosófica se nos presenta como una indagación de la verdad cuya relación con el mundo está mediatizada 
ción de la verdad cuya relación con el mundo está mediatizada por el lenguaje. Con otras palabras, esta filosofía no transfiere a su dominio un tipo de racionalidad técnico científica que, en su forma contemporánea se asimila al sistema lógico-formal axiomatizado, lo cual no significa un rechazo a la práctica racional, siempre que se la comprenda a la luz de su origen dialógico.

Frente a las concepciones reduccionistas del lenguaje que lo tratan como objeto de las ciencias lingüísticas, se destaca su tesis fundamental, de la experiencia plural e imprevisible, de apertura fecunda y sin límites, de una dialéctica dialógica (lo cual no es un pleonasmo) cuya piedra de toque es la vida del lenguaje con todo su precipitado histórico.

El cuestionamiento de la imagen axiomática de la racionalidad en el dominio hermenéutico conlleva no solamente la superación del pensamiento por oposiciones estrictas (v.g. la de sujeto/objeto) sino, además, la crítica incesante al dogmatismo teorético en todas sus formas, ya sean científicas o filosóficas. Se trata de delimitar el discurso lógico-conceptual desarrollado sobre la base de una concepción monológica de la razón sostenida por un sujeto 'puro' quien. ya sea en la duda metódica o la reducción fenomenológica, ha neutralizado la dimensión dialogal del lenguaje -es decir, el lenguaje mismo- en busca de datos inmediatos, de evidencias racionales, de indiscutibles verdades, independientes de las contingencias históricas. Lo cierto y demostrado con arduos análisis fenomenológicos es que no existen datos 'puros' ni en el dominio perceptivo ni en el enunciativo. Max Scheler analizó la 'percepción pura' presuntamente adecuada al estímulo sensible o psicológico, concluyendo que esta pretendida correspondencia entre el percibir y lo percibido “...es más bien el producto final de un violento desencanto, una ultima reducción del exceso de fantasía que rige todo el proceso de 
nuestro ver. La percepción pura es una abstracción" (1) escribe Gadamer quien, de su parte, insistirá en que también los 'enunciados puros' son producto de la abstracción. El ABC de su hermenéutica es el reconocimiento de que toda forma discursiva contiene prejuicios implícitos, motivaciones irracionales.

Nuestro tiempo es pródigo en pensadores que toman como modelo el lenguaje artificial de los matemáticos, garantía de claridad, univocidad, precisión, eliminando la imperfección de las lenguas naturales, la ambigüedad y el hechizo de las jergas que ejercen "una función de exclusión (...) un peligro para el lenguaje filosófico asi como la invasión de nomenclaturas técnicas es un peligro en el hablar cotidiano. Sea que se trate de formas que remontan al idealismo especulativo, o de la jerga de la fenomenología, de la teoría positivista, del marxismo o de la autenticidad-inautenticidad, se pierde el contacto inmediato con la realidad" (2).

La hermenéutica filosófica ha de analizar y resistir estas alienaciones y para ello cuenta con el recurso a la retórica, cauce de comunicación de los discursos científicos. La ciencia debe su influencia a este arte de hacer comprensible lo incomprensible, de trasladar al dominio de lo verosímil la certeza del cálculo, la exactitud del axioma, la proposición enunciativa. Si Gadamer se aproxima al ámbito de la retórica es porque la considera "el único abogado de un concepto de verdad que defiende lo probable, el 'eikos', lo evidente según la razón común sobre las

(1) Gadamer, Hans-Georg, Los fundamentos filosóficos del siglo XX, en Gianni Vattimo (comp.) La secularización de la filosofía. Hermenéutica y posmodernidad, Barcelona, Ed.Gedisa, 1992, p. 103.

(2) Gadamer, H-G., La philosophie dans la societé moderne en L'art de comprendree, París, Aubier Montaigne, 1982, p. 23. 
pretensiones de demostración y certeza de la ciencia" (3). Lo evidente convence, tiene sus razones, se impone por sí mismo aunque no se demuestre.

Así la hermenéutica como la retórica amplían su dominio en proporción directa con el progreso científico y su conversión en un factor social de la vida. Cuando Descartes, el adversario de lo verosímil, comunica y justifica el nuevo concepto de método con recursos retóricos, no mediante demostraciones apodícticas; cuando las exposiciones de la ciencia moderna exceden al círculo de los expertos para ingresar en las convicciones sociales, se debe también a la retórica. La proximidad de ésta al texto gadameriano permite desechar "la apariencia de que la hermenéutica se ciñe a la tradición estético-humanista y (...) se refiere a un mundo del sentido contrapuesto al mundo del ser real y que se prolonga en la tradición cultural" (VM II:230) ¿A qué se debe esta apariencia sino a la difusión esquemática de esta filosofía polifacética, irreductible a toda síntesis?

Bien leída, la obra de Gadamer da respuestas a comentarios unilaterales, a las objeciones que provoca y refuta los diversos intentos de su transposición a términos claros y distintos. Veamos algunos ejemplos: Paul Ricoeur presenta como antinomia dramática de nuestro tiempo a la filosofía hermenéutica vs. la crítica de las ideologías y propone reemplazar el debate por un 'círculo viviente' al sostener que "la hermenéutica de las tradiciones sólo puede cumplir su programa si introduce una distancia crítica (...) y la crítica de las ideologías si incorpora cierta regeneración del pasado, una reinterpreta-

(3) Gadamer, H-G., Verdad y Método II, Salamanca, Ed. Sígueme, 1992, p. 29 (VM II). 
ción de la tradición" (4). Es decir, mientras adosa a Gadamer una meditación sobre la noción de pertenencia a la tradición, los prejuicios y la autoridad, entiende que la obra de J. Habermas desenmascara los sistemas ideológicos, abriendo el camino, mediante el distanciamiento, a la liberación racional. Así presentadas, ambas filosofías renovarían las tesis del romanticismo y la ilustración respectivamente. Pero, ¿dónde queda el planteo de la antinomia 'dramática' cuando Gadamer descarta entre tradición y razón esta antítesis abstracta y afirma su relación ambivalente? La antinomia, con sus palabras, "ignora una verdad, y esto tiene unas consecuencias funestas porque atribuye un falso poder a la abstracción y se ocultan, desde una visión idealista, las verdaderas dependencias" (VM II:236).

Otro ejemplo a destacar lo ofrece Maurizio Ferraris cuando confronta la hermenéutica con la deconstrucción de la metafísica en la obra de J. Derrida subrayando la proximidad de ambas posiciones; tiene razón cuando afirma que la constitución dialógica de la hermenéutica lesiona la metafísica moderna: "Es asi como Gadamer puede sostener que su ontología hermenéutica, no menos que la gramatología de Derrida, prosigue lo esencial del proyecto de la 'destruktion' heideggeriana" (5). La duplicidad de los modelos 'clásico vs. Vanguardia' se atenúa desde que ambos filósofos producen una ruptura con la metafísica tradicional. Gadamer se sitúa fuera de todas las escolásticas que acompañan siempre a la filosofía como el reverso de una medalla a su anverso. Considerar al lenguaje desde el diálogo implica el abandono de toda fijación terminológica que,

(4) Ricoeur, Paul, Ética y Cultura, Buenos Aires, Ed. Docencia, 1986, p. 28.

(5) Ferraris, Maurizio cfr Gadamer y Derrida: La alternativa entre diálogo y escritura y las ambigüedades del romanticismo en AAVV, Pensamiento italiano contemporáneo, Rosario, Santini Gráfica, 1988. 
si bien necesaria en la investigación científica, debe ser superada en la dinámica del pensamiento filosófico.

La superación de la metafísica es posible porque es posible la relación dialógica entre el hombre y el mundo, porque el lenguaje común permite, no sólo dejar de lado la ontología de la sustancia sino pensar el sentido del ser en forma no metafísica, a la manera de Heidegger quien "cuando se pregunta por el sentido del ser no piensa el sentido a la manera de la metafisica y según su concepto de esencia, sino que lo entiende como el sentido de aquella pregunta que no espera una respuesta determinada, sino que más bien indica una dirección del interrogar. He dicho alguna vez que sentido es sentido direccional" (6).

Sin embargo, Ferraris concluye en que Gadamer encuentra su punto de apoyo en la metafísica del Logos viviente para asegurar la continuidad ininterrumpida de la tradición y la supervivencia de un sentido sin arriesgar la hipótesis de su posible ruptura. Es decir, una decisión 'metahistórica', un acto de fe en el modelo de lo clásico vendría a afirmar la vitalidad de la tradición que "no es un evento determinado en forma históricoempirica por lo que eventualmente podría interrumpirse a causa de guerras, diluvios universales, hogueras de bibliotecas" (7).

Advertimos que cuando los intérpretes de esta hermenéutica se refieren al rol que juega el concepto de tradición aluden a un significado unívoco equivalente a tradición histórico-cultural sin atender a la complejidad semántica del término, a su potencial de sentidos y de cosas no explicitadas que llevan a Gadamer a la aclaración de que sólo por error se ha convertido a

(6) Gadamer, H-G., Deconsstruzione e interpretazione en aut aut $\mathrm{n}^{\mathrm{a}} 208$, 1985, p. 33.

(7) Ferraris, M., art.cit., p. 106. 
la tradición en un supersujeto pues cuando habla de ella no debemos entender "ningún sujeto colectivo, sino que esa tradición es el nombre común para designar cada texto concreto (en el sentido más amplio de la palabra texto) incluyendo una obra plástica, una construcción y hasta un proceso natural" (VM II:357).

Por consiguiente, la relación hermenéutica-tradición no dependería, según leemos, de decisiones suprahistóricas, ni estamos ante una hipóstasis del pasado pues se manifiesta en cada texto y, sobre todo, en el lenguaje común donde no hay lugar para palabras descontextualizadas ni para definiciones unívocas. Este discípulo de Heidegger insistirá en el hecho de que el lenguaje calla más de lo que manifiesta, oculta además de expresar, pero esto no significa "que la expresión verbal sea inexacta y esté necesitada de mejora, sino que justamente cuando es lo que puede ser trasciende lo que evoca y comunica" (VM II:175). Es propio del lenguaje una constante ambigüedad donde los signos se despliegan y repliegan en equilibrio inestable.

Se ha afirmado que esta hermenéutica ha venido a 'urbanizar' al pensamiento heideggeriano, es decir, lo ha incorporado y modelado, a través de su propio pensamiento, al lenguaje común, público, urbano. La frase de Habermas es leída en otro sentido cuando se afirma que Gadamer, con la urbanización, replantea, de manera original, la identificación ser-lenguaje (como se da en Heidegger) al acentuar el polo del lenguaje frente al del ser, con lo que se logra la posibilidad de nuevas lecturas sobre Heidegger, que marcan, por ejemplo, su proximidad a Wittgenstein (8).

(8) Vattimo, Gianni, Verdad, retórica, hermenéutica. Observaciones sobre $H-G$. Gadamer en Revista de Estética, ccayc, Buenos Aires, $\mathrm{n}^{\mathrm{a}} 2$ 2, 1984, p. 27. 
Puede afirmarse que lo dicho por Heidegger sobre el misterio del ser es aplicado por Gadamer al lenguaje, de modo tal que la relación prevalece sobre sus miembros; podemos comparar los significados de estos términos con aquellos cuerpos cuyas moléculas tienen tan escasa cohesión que toman la forma del vaso que los contiene. Y más aún: el lenguaje no es un continente que contenga la fluctuación de los significados, él mismo es fluctuación semántica, de suerte que la conceptualización filosófica implica una reducción de sentido, pues "el desligar del todo una palabra de su contexto para insertarla en un contenido preciso que la convierta en palabra conceptual. corre el riesgo de vaciarla de sentido" (VM II:349 s).

Gadamer logra dar nueva vida a estas creaciones conceptuales en el modelo del diálogo que viene a aclarar la estructura de la participación, instancia que permite despejar las dudas y malentendidos que suscita el texto gadameriano. G. Vattimo distingue los elementos constitutivos de la ontología hermenéutica: señala el rechazo de la objetividad, es decir, del modelo metódico de las ciencias positivas como ideal del conocimiento histórico, pues Gadamer observaría el objetivismo historiográfico como un error de método; aclara entonces que "el dominio de la objetividad no puede, como tal. ser sometido mediante el reconocimiento teórico de un error de método" (9).

Sin embargo, Gadamer de ningún modo cuestiona el dominio de la objetividad; lo que él dice es que "el saber no se plantea sólo como problema de controlabilidad de lo otro y de lo extraño (...) Yo afirmo que lo esencial de las ciencias del espíritu no es la objetividad, sino la relación previa con el objeto. Yo completaría para esta esfera del saber, el ideal del

(9) Vattimo, G., Las aventuras de la diferencia. Pensar después de Nietzsche y Heidegger, Barcelona, Ed. Península, 1990. P. 34. 
conocimiento objetivo, implantado por el ethos de la cientificidad con el ideal de 'participación'. Participación en los temas esenciales de la experiencia humana tal como se han plasmado en el arte y en la historia..." (VM II:313). Como vemos, no descalifica al objetivismo historiográfico como error de método, sólo rechaza el incremento de metodologismo a secas en las ciencias del espíritu, consecuente con la crítica (que la filosofía viene desarrollando desde Hegel) a la escisión propia de la cultura moderna entre subjetividad y objetividad. Con su dialéctica, Hegel buscaba sustituir el carácter unilateral en la pretensión de verdad absoluta de ambos principios por un discurso universal -el de la lógica- que asignara a los demás discursos, por contradictorios que fuesen, una participación gradual en el conocimiento de la verdad.

A diferencia de la dialéctica antigua, de carácter propedéutico, cuya realización consistía en llevar a su extrema radicalización las contradicciones. Hegel asigna a su dialéctica la tarea positiva de llegar a una verdad que reconcilie -no que suprima y niegue- las oposiciones, así la de subjeto-objeto. Aportación decisiva de Hegel fue haber introducido la problemática histórica en la conciencia filosófica, de manera que a pesar de algunas diferencias esenciales -a las que nos referiremosla hermenéutica actual presenta una línea de parentesco con el pensamiento hegeliano.

En Heidegger y Gadamer es insoslayable la dimensión de la historicidad desde la cual la dicotomía sujeto/objeto es ontológicamente irrelevante. La clave heideggeriana para suprimir la dupla la encontramos en el fenómeno unitario del Dasein como ser-en-el-mundo; este 'ser-en' no se comprende como una relación espacial sino de familiaridad 'con' el mundo que se expresa en su ser-con otros. Esta unidad esencial en la estructura del Dasein significa la transposición del ámbito subjetivo de la 
conciencia al ámbito abierto del mundo y, por consiguiente, el distanciamiento del sujeto cartesiano; es decir, la trascendencia no es pensada por Heidegger en términos de interés metafísico, sino como aquello que está en la misma estructura básica del Dasein, de tal manera que la comprensión de sí no surge -desde la perspectiva de esta hermenéutica de la facticidad- de la conciencia. está determinada por la relación del yo con las cosas y las circunstancias del mundo. La metafísica tradicional -desde Platón a Nietzsche- es cuestionada por haber concebido al ser como sustancia, reificación que se desentiende de la conexión esencial entre el Dasein que pregunta por el ser y el ser mismo.

De su parte, Gadamer fundamenta la crítica a la subjetividad del yo en su concepción del lenguaje, cuya relación con el mundo no es objetivable. Mientras la experiencia lingüística reviste el carácter absoluto, la objetividad científica resulta relativa y segmentada de esta lingüisticidad donde subyace la antigua reciprocidad entre hombre y mundo postulado por la filosofía del Logos. La traducción de Logos como razón, aunque legítima en la medida en que "es la razón misma de las cosas la que se representa en un modo especifico de discurso: enunciado, proposición o juicio" (VM II:53) resulta insuficiente desde la perspectiva hermenéutica.

En opinión de Gadamer, débese a Hegel el haber restaurado al saber absoluto "como la verdad de la metafísica a la manera, por ejemplo, como pensó Aristóteles el Nous o Tomás el Intellectus agens (...) Su concepto del espíritu, que trasciende las formas subjetivas de la autoconciencia, se retrotrae, por tanto, a la metafísica del Logos/Nous de la tradición platónica-aristotélica, que antecede a toda la problemática de la autoconciencia. De este modo, Hegel ha logrado dar cima a su tarea de vol- 
ver a fundamentar el logos griego en el terreno del espíritu moderno que se sabe a sí mismo" (10).

La traducción limitada del logos por la ratio latina ha orientado dicho logos hacia la razón del sujeto cartesiano y al concepto moderno de método, dominio de la claridad y la evidencia propias del discurso axiomático. Es tan amplia y generalizada la comprensión del logos como pensar lógico de la razón, que se llega a remontar tal concepción al mismo Heráclito cuando sentenciaba que conviene seguir al logos, general a todos y común a todos, y no vivir como si se tuviera una inteligencia particular, propia de los hombres que están dormidos (af. 2). Carlo Sini opina que este logos 'común a todos' es el pensamiento lógico, fundamento del saber occidental que se remonta al sabio de Efeso y que Platón y Aristóteles elevaron a un método cuyo objetivo es la visión pública, panorámica y universal de los hombres despiertos (11). Con esto queda despejada la mítica oscuridad del filósofo griego, pues se presenta como un iluminado por la luz racional del logos.

La hermenéutica viene a rescatar la riqueza semántica al logos cuando lo comprende como lenguaje y a éste en un sentido irreductible a lo lógico-enunciativo. Recordemos que para Heidegger el logos es un darse del ser que no se agota jamás, ya que siempre se repliega sobre si mismo, ambigüedad que impide su determinación a nivel del pensamiento representativo. La verdad como aletheia es el develamiento y el oculta-

(10) Gadamer, H-G., La idea de la lógica de Hegel en La dialéctica de Hegel, Madrid, Ed. Cátedra, 1988, p. 79..

(11) Sini, Carlo, cfr. Semiótica y hermenéutica en AAVV, Pensamiento italiano contemporáneo, pp. 83-95. 
miento del ser, verdad olvidada por la metafísica como ciencia del ente.

Gadamer asimila de Heidegger su enseñanza de que la verdad es revelación y ocultamiento, esta ambigüedad es transferida al lenguaje, de tal modo que lo que se oculta viene a ser como el reverso de la palabra: "sólo lo silenciado convierte lo dicho en palabra que puede alcanzarnos (...) Los conceptos en los que se formula el pensamiento, emergen de un muro de oscuridades" (VM II: 398). Conviene no perder de vista la distinción entre certeza y verdad; no es solo la certeza de un enunciado lógico lo que se cuestiona sino su verdad, ésta tiene que ver con sus presupuestos, con sus motivaciones no enunciadas, con la pregunta a la que responde, pregunta que a su vez es una respuesta y así ad indefinitum. Tal es la dialéctica en la que participamos, tal el matiz de inspiración platónica que denuncia su pensamiento.

Concebido el lenguaje como un proceso dialéctico de alcance universal, hasta el sentido del juicio lógico y la demostración científica queda referido a la comprensión de su historia motivacional. La ocasionalidad resulta ser la esencia misma de todo discurso y su determinación semántica. La ocasionalidad del hablar humano "...no es una imperfección eventual de su capacidad, sino más bien expresión lógica de la virtualidad viva del hablar, que sin poder decirlo enteramente pone en juego, sin embargo, todo un conjunto de sentido" (12).

La hermenéutica fuera de toda duda, no cuestiona la legitimidad de ningún discurso si bien ninguno puede arrogarse la pretensión de manifestar una verdad excluyente y/o exclusiva.

(12) Gadamer, H-G., Verdad y Método I, Salamanca, Ed. Sígueme, 1977, p. 549 (VM I). 
Por ejemplo. la explicación copernicana no logró cancelar ni la apariencia real ni el hablar común o poético de que el sol 'sale' al amanecer y se 'pone' en el ocaso. Ante el todo del lenguaje "no existe ninguna incompatibilidad entre el sostenimiento de ciertas apariencias y la comprensión racional de que en el mundo las cosas son a la inversa" (13). Puede acontecer que en el poema el lenguaje coincida (para seguir con el ejemplo) con la visión copernicana; así, E. Meister escribe: ?El viejo sol/no se mueve/de su sitio?; en los versos subyace la cosmovisión heliocéntrica: pero, ¿quién sino el poeta puede llamar al sol 'viejo'? En este decir no se alude a las distancias infinitas que aterraban a Pascal, este 'viejo' nos es familiar, nos inspira ternura y tristeza (14).

Lo único absoluto (aquí valga el término) es la experiencia lingüística entendida como relación fundamental lenguaje-mundo. En esta hermenéutica se formulan de modo original ciertos problemas con los que el pensar filosófico convive desde la antigüedad, si bien dichas relaciones de familiaridad se muestren perturbadas por el auge del cientificismo. Parménides supo identificar el pensar con el ser, de tal manera que el conocimiento no dependía de la actividad de un sujeto cognoscente, sino de una relación de pertenencia al ser. De su parte, Gadamer, cuando se refiere a la vinculación de todos los discursos con el lenguaje, de todo acontecer con el comprender, siente que está retrocediendo hasta el filósofo de Elea.

Por eso cuando afirma: "nosotros pensamos desde el lenguaje como centro" (VM I:552), conviene observar la preposición 'desde' que denota el lugar a partir del cual ha de hablarse de las cosas y connota su rechazo a las concepciones

(13) Gadamer, H-G., Ibidem, p. 538.

(14) Gadamer, H-G.. Poema y Diálogo, Barcelona, Gedisa, 1993, p. 154. 
instrumentalistas del lenguaje; éste no es una herramienta 'con' la que se pueda pensar, hablar o poetizar. Hablar de uso lingüístico es evocar representaciones incompatibles con nuestra experiencia, es suponer que las palabras están disponibles para ser usadas según nuestra conveniencia y necesidad; el lenguaje no depende de la conciencia del hablante, al contrario él prescribe su uso. "No se trata de ninguna mitologización del lenguaje sino que el fenómeno expresa una exigencia no reducible a la opinión subjetiva e individual. Nosotros, ninguno en particular y todos en general, hablamos en el lenguaje, tal es el modo de ser del lenguaje" (VM II:193). La única analogía que le cabe es la de un juego que nos juega, no que podamos jugar con la conciencia despierta; se trata de un proceso dinámico que la hermenéutica ilustra con el arte del diálogo.

Pero no hay que confundirse: el lenguaje en el que somos y nos movemos tiene dimensión universal y no es una hipóstasis, ni una idea ni un absoluto. Así como en Heidegger el 'ser' no es un ente ni lo que él significa es comparable con la significación de ente alguno, en Gadamer tampoco el lenguaje tiene el sentido de un ente, se trata de una universalidad que no puede ser sometida a un tratamiento objetivante ni circunscripta en una definición conceptual; no es 'en sí' ni es relativo a una lengua determinada, a un determinado hablar humano: "...la esencia del lenguaje implica una inconsciencia realmente abismal del mismo (...). Sólo podemos pensar dentro del lenguaje y esta inserción de nuestro pensamiento en el lenguaje es el enigma más profundo que el lenguaje propone al pensamiento" (VM II: 147).

Resumiendo: la experiencia lingüística no depende de la conciencia individual ni es una suma de todas ellas, fenómeno comprobable a nivel del habla cotidiana donde se ocultan los 
aspectos tematizados por la ciencia como las estructuras y reglas gramaticales, sintácticas o semánticas; el autoolvido es propio del lenguaje mismo, del que existe el diálogo -no es el sistemadel que vive en la conversación y. se desenvuelve en contextos de significados cuya nota distintiva es la apertura. Con palabras de Gadamer: "El lenguaje posee una fuerza protectora, de forma que lo acontecido en él queda sustraido a la reflexión y permanece, en cierto modo, resguardado en el inconsciente. Una vez que se conoce esta esencia del lenguaje, hay que franquear necesariamente las dimensiones de la lógica enunciativa y buscar horizontes más amplios" (VM II:194).

¿Y dónde vislumbra Gadamer horizontes más amplios? Los aspectos que acabamos de reseñar y refieren a la ambigüedad esencial del lenguaje, están anticipados en la filosofía heideggeriana del ser, cuyo lugar esencial es buscado en el lenguaje del comienzo, el de los primeros pensadores griegos. Es en los presocráticos donde el ser habla en el modo de callarse, es remontando hasta la vertiente matinal del pensar donde Heidegger cree encontrar lo que emerge de lo que siempre se oculta (así la fisis en Heráclito), donde el ser aparece como lo que dispensa la presencia (según Anaximandro), ambigüedad que bien puede ilustrarse con la figura trágica de Edipo donde se da la conexión originaria entre ser y aparecer en su aspecto de lucha. Desde Platón la escisión del ser y aparecer será decisiva para la historia de la metafísica, pero en este camino "El Ser engendra la nube que lo oculta, la Idea se vacía, la forma no es más que forma donde toda revelación se calla" (15).

Gadamer insiste sobre este discurrir del lenguaje en dos direcciones: una que tiende hacia la objetividad del pensamiento

(15) Fontaine-De Vischer, Luce, La pensée du langage chez Heidegger en Revue Philosophique de Louvain, $n^{\mathrm{a}}$ 82, 1966, p. 241. 
y que implica, por consiguiente, cierta distancia del hablante respecto de las cosas. Los griegos no lograron dar adecuadamente con el ser específico del lenguaje, pues entendieron que en éste hablan las constelaciones objetivas, el mundo pensado como ente a través de la conformación lingüística del enunciado (cfr. VM I:534). Estamos ante una determinación parcial del lenguaje que cumple otro movimiento, inverso: el que va desde la objetividad del pensamiento a la fuerza cobijante de la palabra: "Lo que el lenguaje, al hablar, hace que sea, no es el ser en la abstracta inmediatez del concepto que se determina a si mismo, sino un ser que habría de describir más bien a partir de lo que Heidegger denomina iluminación" (16). Ambos pensadores se refieren reiteradamente a esta franja de indeterminación que se da con la palabra y, de modo privilegiado, en el decir poético que viene a complementar la condición del espíritu moderno; no se trata de yuxtaponer lo inefable a lo decible, lo inescrutable a lo cognoscible, ya que la lingüisticidad de la experiencia del mundo, tal como es comprendida por la hermenéutica es un todo que todo lo abarca.

Si Hegel tenía razón cuando aludía al instinto lógico del lenguaje que tiende a la determinación del concepto, podemos afirmar -en ajustada paráfrasis- que se mueve además por un instinto poético, aquél que se significa a si mismo y tiene, como la pieza de oro de Paul Valery, su propio valor, a diferencia de la moneda de circulación corriente con la que compara a los otros signos.

Cuando Gadamer escribe 'El ser que puede ser comprendido es lenguaje' corresponde interpretarlo en su contexto, atendiendo a todos los matices con que medita sobre el 'ser', el 'comprender' y el 'lenguaje'. Uno de los intentos de

(16) Gadamer, H-G., La dialéctica de Hegel, p. 102. 
despojar al texto gadameriano de su complejidad semántica lo hace Vattimo cuando afirma que mientras Heidegger puso en evidencia la problematicidad del vínculo entre ser y lenguaje o sea la imposibilidad de la determinación del ser, pues no se llega a afirmar que sea una u otra cosa, Gadamer si llega a su descripción cuando lo identifica con el lenguaje; así leemos: “...el 'es' de estos enunciados es dificil de entender en su verdadero alcance: para la ontología hermenéutica sigue siendo, a pesar de cualquier referencia a Heidegger, el 'es' de la metafisica, descripción de esencias simplemente presentes" (17).

Cuando Gadamer se refiere a la dimensión situacional, a la historicidad de todo enunciado está manifestando que "...un enunciado es algo más que la simple actualización de un fenómeno presente, significa ante todo que pertenece al conjunto de una existencia histórica y es simultánea con todo lo que pueda estar presente en ella" (VM II:60); reflexiones que podemos aplicar al lenguaje mismo de su hermenéutica, para evitar el riesgo de caer en lecturas precipitadas y unilaterales. El mismo Gadamer, ante el éxito que logró la expresión -separada de su contexto- tuvo que aclarar: "Cuando acuné la frase 'El ser que puede ser comprendido es lenguaje' dejaba sobreentender que lo que es, nunca se puede comprender del todo (...) esto porque lo mentado en un lenguaje rebasa siempre aquello que se expresa (...). Tal es la dimensión hermenéutica en la que el ser se muestra" (VM II:323)

Podemos resumir así: el 'ser' gadameriano ni es el ser de la metafísica ni describe esencias simplemente presentes pues los términos troquelados en el discurso filosófico, surgidos del lenguaje común, no son signos fijos ni designan algo unívoco. El riesgo de la conceptualización filosófica es el empobrecimiento

(17) Vattimo, G., Las aventuras de la diferencia, p. 18. 
de lo semántico, el vaciamiento de sentido que se produce al separar las palabras de su medio natural, es decir, del lenguaje donde viven, se modifican, mueren o se dinamizan en el intercambio comunicacional de los interlocutores; el rol del filósofo consiste en reanimar la fuerza intuitiva del lenguaje para ampliar el entendimiento humano.

Advertimos una acentuada discrepancia entre Heidegger y Gadamer para desmontar los conceptos ya que, en el primer caso, asistimos a una búsqueda de la experiencia del ser en el ámbito de la palabra presocrática, mientras de su parte, Gadamer sostiene que es en el lenguaje ordinario, en la conversación determinada por la lógica de pregunta y respuesta donde desaparece la ontología de la sustancia.

La regresión de Heidegger a la experiencia primigenia del ser, suscita en el discípulo reflexiones contundentes: "En realidad no es posible dar con el comienzo ni siquiera en la historia de los propios orígenes. El comienzo retrocede siempre hacia lo incierto, como le ocurre al paseante costero en la célebre descripción que hace Thomas Mann de la regresión en el tiempo en La montaña mágica: detrás del último promontorio aparece siempre otro nuevo en una situación interminable" (VM II:351).

Gadamer encuentra en la conversación socráticaplatónica no solo el modelo de la estructura dialogal del lenguaje sino el arte de superar los conceptos de los escolásticos y el punto de apoyo para su crítica a la subjetividad de la autoconciencia; en el transcurrir del diálogo la instancia del yo queda anulada, es en la esfera del nosotros donde se desarticulan los subjetivismos, donde los pensamientos 'fuertes' y las posiciones absolutas pierden justifican y sentido. No hay principio superior 
al de la apertura al diálogo, siempre que implique el reconocimiento de una probable superioridad del interlocutor.

La estructura del ser-en-el-mundo se transforma en la del ser-en-el-diálogo, dinamismo que modifica convicciones, anula prejuicios, permite que el yo salga de sí mismo con la alternativa de regresar a sí siendo otro. Los límites entre yo y tú, yo y mundo, intérprete y texto a interpretar quedan desdibujados en este proceso donde es fundamental la búsqueda de un acuerdo; pero éste no tiene un sentido coercitivo, no se trata de que el otro adhiera a mis propias opiniones: "La conversación no es posible si uno de los interlocutores cree absolutamente en una tesis superior a las otras, hasta afirmar que posee un saber previo sobre los prejuicios que atenazan al otro. El mismo se implica asi en sus propios prejuicios" (VM II:117). Nuestro autor reitera: "...el análisis hermenéutico tiene que eliminar claramente un falso modelo de comprensión y de acuerdo. En el acuerdo, además la diferencia nunca se disuelve en la identidad (...) Hay co-incidencia, como dice bellamente el término" (VM II:23).

No debemos confundirnos: si bien es cierto que el monólogo cede paso al ejercicio del diálogo, suelen darse relaciones dialógicas ficticias como en el caso del interlocutor que acorrala al adversario procurando el asentimiento a la verdad que sostiene: este presunto diálogo es una variante del soliloquio clásico pues no se cuestiona el predominio de la razón sujetocéntrica; que el filósofo recurra al diálogo por razones formales/ estilísticas no constituye una alternativa radical. Por otra parte, existen monólogos de estructura diálogica como el que, al pensar (según Platón) sostiene el pensamiento consigo mismo.

Si, según el filósofo clásico y Gadamer, pensar es dialogar, se debe a que la diferencia funciona como condición de 
posibilidad para la existencia del diálogo. La 'diferencia' es el primer nombre de la hermenéutica, tiene el sentido de una división originaria y es la forma obligada en la que se constituye la universalidad.

En ese arsenal filosófico no encontraremos ninguna pretensión exorbitante, ninguna mirada sub especie aeternitatis ni interés alguno en llegar a verdades definitivas que no se discutan, independientes de las contingencias históricas y de las incidencias sociales. El filósofo que asuma una relación dialógica auténtica, de crítica argumentada, debe correr el riesgo de ser cuestionado, de exponerse a cambios imprevistos, inversión decisiva de esta dialéctica respecto de otras concepciones (tal la hegeliana) donde se reduce a esquemas formales enunciables en tesis, según los términos de la conceptualidad clásica y se despliega hasta su término absoluto.

En la dialéctica gadameriana, la apertura ilimitada del logos al diálogo y la noción de racionalidad técnico-científica, encuentran su punto de apoyo no solo en la historicidad y lingüisticidad constitutivas del 'ser-en-el-diálogo' sino en la concepción de la estructura numérica del logos, tal cual fue expuesta en los textos platónicos. La lectura de que ellos hace Gadamer se inscribe en la línea crítica a la noción de sistema que se inicia en Kierkegaard y le permite, con método fenomenológico, deducir la dialéctica a partir del diálogo en obra temprana (Platos dialektische Ethik, 1931).

Frente a la concepción generalmente admitida (desde las investigaciones de Julius Stenzel) que sotiene una evolución en el pensamiento platónico a partir de la doctrina de las ideas hasta su crisis en el Parménides, nuestro filósofo arriesga la tesis de que, ya en los diálogos anteriores, se observan consideraciones referidas a la estructura numérica del logos; así en 
Protágoras se plantea el problema de la relación de lo uno y lo múltiple a propósito de la virtud: se trata de saber si las virtudes se diferentes o tienen un denominador común; en el diálogo no encontraremos pruebas, como en la sistemática deductiva de la geometría euclidiana, para el reconocimiento de la verdad; pues una cosa es la certidumbre del conocimiento personal y otra, muy distinta, del que se configura en enunciados irrefutables. En el Parménides, Platón se refiere a la dificultad de dar pruebas cuando se trata de la hipótesis de las ideas, estableciendo la diferencia entre su propia evidencia y la posibilidad de demostrarla al adversario: "Si alguien dijera que a las formas (...) no les corresponde el ser conocidas, a quien tal dijera no podría mostrársele que se equivoca" (133b).

Pero, las lecturas que intentan mostrar en Platón un ascenso ordenado hacia el mundo de las ideas son erróneas, la hermenéutica debe desterrarlas, disipar (como el Filebo) la apariencia engañosa de un abismo infranqueable entre el mundo ideal y el sensible. En opinión de Gadamer, el concepto de lo bello, no restringido a lo estético y cuya esencia es manifestarse, representarse, viene a cerrar el hiato entre lo sensible y lo inteligible, ilustra la identidad del ser y del aparecer, de la idea y del fenómeno, distinciones que se resuelven en la indistinción de los términos. Hay que volver la mirada y aguzar el oído hacia la comunidad del diálogo que es donde se juega la hipótesis (no la doctrina) de las ideas, cuyo entrelazamiento dialéctico no conduce a la representación de una pirámide de conceptos inequívocos, semejante a un eleatismo atomístico. El mismo Platón consideró insuficiente, para comprender el conocimiento, la concepción de un eidos común con el que relacionar los fenómenos.

El problema es comprender cómo, en el pensamiento, lo uno puede ser varios y los varios, uno; es aquí cuando acude 
al número, 'unidad de una pluralidad resumida' para ilustrar la estructura formal del logos. Un simple ejemplo muestra la vinculación de lo uno con lo múltiple: la palabra significa, pero no como una suma de las letras que la componen, sino como un todo; la proposición también es concebida sobre el modelo del número, no según la estructura predicativa del juicio a la manera de Aristóteles, pues Platón concibe al logos como el lugar de reunión de las ideas. El enigma dialéctico de lo uno y lo múltiple, que tuvo sobre ascuas al filósofo griego, encontró su confirmación en la especulación trinitaria de la Edad Media que trajo como novedad, a diferencia del logos antiguo, la esencia histórica del lenguaje, el puro suceder de la palabra, vinculada al acontecimiento de la redención.

Pero, al observar Gadamer que la estructura del logos y del verbo, tal como se reconoce en la dialéctica platónica y medieval, solamente es reflejo de sus contenidos lógicos, propone otra dialéctica de la palabra, más abarcante, desde que involucra al conjunto de la lengua y a la acepción del mundo que la sostiene. El movimiento se da ahora entre los polos de la finitud del hablar humano y la infinitud de un sentido a interpretar, totalidad de un significado que no se puede decir totalmente. Esto es dar por sentado que el discurso hermenéutico se alimenta de lo semántico y de lo no semántico.

Logos es relación, lo dice el Extranjero de Elea a Teetetes: "...puesto que tanto el ser como el no-ser comparten la misma dificultad, nos queda la esperanza de que cuando uno de ellos se muestre, también el otro se mostrará; y si no podemos ver a ninguno, seremos al menos capaces de hacer que el razonamiento se abra camino con mayor facilidad en medio de ambos" (Sofista, 251a). Sobre estos textos solo podemos avanzar dando rodeos, según el consejo de Boyg a Peter Gynt, pues no están expuestos en forma lineal ni clara ni distinta, lo 
que se juega es una especie de tierra de nadie que no ha sido enunciada, un amplio abanico de lo no-dicho. Gadamer insiste sobre la potencialidad e imperfección de la palabra humana y en la finitud del entendimiento discursivo, aunque postule la infinidad de la dialéctica y la apertura inacabable del saber a semejanza de la serie numérica que no clausura.

El logos platónico se presenta como el prototipo del discurso hemenéutico, que es relacionalidad llevada a cabo en y por el diálogo: "El logos es el logos en el que uno se distingue de lo otro y se relaciona con lo otro" (18) dirá Gadamer con acento platónico.

El segundo nombre de la hermenéutica es, por consiguiente, relación. El lenguaje se corresponde originariamente con el mundo, ambos se pertenecen mutuamente en la medida en que el mundo habla en el lenguaje y éste existe porque representa al mundo; así la conformación lingüística de nuestra experiencia involucra la interacción de lo propio y lo ajeno, fusión de horizontes. En el campo hermenéutico, el diálogo -que es donde se da el lenguaje- es el modo fundamental de articular la realidad $y$, en relación al platonismo, el medio adecuado para cuestionarlo en su momento intuitivo de conocimiento de las ideas, separado de la mediación lingüística: "Elevarse sobre los nombres quiere decir que la verdad de la cosa no está puesta en el nombre mismo. No significa que el pensamiento pueda prescindir de usar nombre y logos. Al contrario, Platón ha reconocido siempre que el pensamiento necesita de estas mediaciones aunque tenga que considerarlas como siempre superables. La idea, el verdadero ser de la cosa, no se conoce si no es pasando por estas mediaciones" (VM II:515).

(18) Gadamer, H-G., M. Heidegger zum 60 en Anteile, Geburstag, Franfurt, 1970, p. 75. 
El diálogo asume la forma de una docta ignoratia que va configurando la actividad filosófica alrededor de la primacía del preguntar sobre el responder. Desde esta perspectiva, Gadamer accede al enciclopedismo hegeliano y rechaza la síntesis omnicomprensiva entendida como autocomprensión en el monólogo de la dialéctica. En el prólogo a La dialéctica de Hegel, confiesa que a pesar de haber pretendido poner claridad en la oscuridad de este pensamiento dialéctico "el resultado fue solo discreto. Entre el Escila de la pedante clarificación lógica y el Caribdis de la incontrolada entrega al juego dialéctico era dificil mantenerse en el punto medio" (19). Lo acertado de la comparación mítica nos permite observar el viaje del pensador como el de Ulises navegando peligrosamente en un mar de profundos remolinos.

No obstante las dificultades que ofrece su lectura de Hegel, destacamos los aspectos a los que adhiere su propio pensamiento de aquellos que son dejados de lado y tienen que ver con el proyecto del saber absoluto. Gadamer estima que el camino más adecuado para acceder al método de la Lógica, transformada por Hegel en ciencia filosófica, debe comenzar en la filosofía eleática, la primera en concebir la actividad de un pensar puro separado de la incidencia de lo sensorial y de la subjetividad de la conciencia, tema a desarrollar en etapas posteriores del pensamiento filosófico: "Es indiferente que sea yo o sea otro quien opine o diga algo. En el pensar es pensado lo común, que excluye, de suyo, todo carácter privado de opinar. El yo es depurado de sí mismo" (20).

Además se subraya el aporte de Platón respecto a la concatenación de las ideas, a la relación de las ideas entre sí; en

(19) Gadamer, H-G., La dialéctica de Hegel, p. 102.

(20) Gadamer, H-G., Op.cit., p. 93. 
este sentido, la primera verdad de la Lógica es de raigambre platónica. A Hegel se debe la profunda captación de la dialéctica clásica en Sofista, Parménides, Filebo, diálogos que "no existian en absoluto para la conciencia filosófica del siglo XVIII $y$, solamente gracias a él, fueron reconocidas como el auténtico núcleo de la filosofía platónica" (21). La característica de la dialéctica antigua es la de ser objetiva pues el espíritu no ha llegado aún a la conciencia de su subjetividad, de su ser-para-sí, del encuentro consigo mismo. En cuanto a la dialéctica hegeliana Gadamer señala el error de las interpretaciones que la identifican con una concepción de la totalidad del mundo en un sistema universal de categorías. No estamos ante la constitución del mero saber de los entes, se trata de comprender el saber de lo sabido es, a su vez, saber del saber: "Sólo porque el objeto sabido no puede ser jamás separado del sujeto que sabe -lo cual quiere decir que cuando está en su verdad es en la autoconciencia del saber absoluto- hay un automovimiento del concepto" (22).

Platón no llegó a distinguir los conceptos puros de la reflexión (tal la identidad y la diferencia, recíprocamente implicadas) de los conceptos cosmológicos (como el movimiento y el reposo). El Timeo resulta, en este sentido, un diálogo ejemplar pues "...refiere que la estructura cósmica pone literalmente ante los ojos del espiritu humano la identidad y la diversidad, de suerte que el hombre, al tomar en consideración la regularidad de las órbitas astrales y sus desviaciones, los fenómenos relacionados con la elíptica, aprende a pensar participando en estos movimientos" (VM II:90). De su parte, Hegel sostiene que los conceptos de reflexión y los de objeto sólo son momentos diferentes de idéntico despliegue; dicho de otro modo, es la unidad

(21) Ibidem, p. 13.

(22) Ibidem, p. 19. 
básica del pensar y del ser lo que encuentra su realización en la doctrina del concepto.

Según Gadamer, la tarea de la Lógica no llega a su plenitud porque la tendencia objetivadora de la razón, del logos apofántico aristotélico (fundamento de la lógica enunciativa) y radicalizado por Hegel, encuentra su cauce en el lenguaje. Hegel comprendió que la lógica presentaba una aporía, 'La inquietud del proceso dialéctico' que debe sublimarse en el saber absoluto. Al pensamiento de la totalidad como saber absoluto, la hermenéutica contrapone la radical finitud de la naturaleza humana, perspectiva desde la cual se contempla el fenómeno del pensamiento y del lenguaje en el discurrir de la dialéctica.

La actualidad de Hegel resulta ser su concepción de la proposición especulativa que no puede reducirse al enunciado pues el pensar se presenta referido a sí mismo. La proposición especulativa, que moviliza al pensar, tiene su existencia en sí mismo (como la palabra poética y toda obra de arte), por ello remite a una totalidad inagotable que no es un ente, pensado por Hegel como la reflexión-en-sí. Mientras lo que muestra el movimiento de la lógica tiene el modo de ser del objeto, el conocimiento de si mismo en el ser-otro presenta el carácter de la autoconciencia. Es en la expresión lingüística de todo pensamiento donde el concepto se transfigura en palabra vinculante; el pensar que objetiva la realidad es reconducido por la hermenéutica a la expresión lingüística del mundo, concebido como el ser-en-el-hombre.

Si hay un punto de contacto entre la hermenéutica y la dialéctica hegeliana es en su dimensión especulativa que implica la idea del reflejo, duplicación especular de una imagen original; una idea especulativa debe entenderse como expresión de "una relación refleja en la que, lo que se refleja, es por su parte, pura 
apariencia de lo reflejado, igual que lo uno es lo uno de lo otro y lo otro es lo otro de lo uno" (VM I:558). Esta relación especulativa se esclarece en el análisis hegeliano de la frase filosófica que, únicamente por la forma aparenta ser una enunciación (atribución de un predicado a un sujeto) puesto que, en realidad, lo que se expresa en el predicado es la verdad del sujeto. Es como si estuviéramos ante una desarticulación funcional de las normas gramaticales, pero así lo requiere el movimiento del pensamiento conceptual.

Dicho de otro modo, en el movimiento de la predicación las determinaciones son extensas al sujeto, a la cosa que puede ser considerada desde diversos respectos y a la cual puede agregársele distintos predicados. En este punto recordemos la distinción entre entendimiento y razón, pues mientras el primero tiene que ver con las distinciones de las determinaciones, la razón especulativa aprehende la unidad de dichas determinaciones en la mismidad del movimiento dialéctico. Lo propio de los juicios del entendimiento es discurrir sobre la cosa como si ésta fuese una sustancia firma, el sustentáculo de sus accidentes. En tanto, el lenguaje filosófico se aparta de estos cánones, rechaza la dupla del sujeto como fundamento inmóvil y de sus predicados como agregados contingentes: "No es que se capte algo nuevo o diferente como predicado, pues al pensar el predicado se está, en realidad, ahondando en aquello que el sujeto es. El subjectum, tomado como fundamento firme es abandonado, puesto que el pensamiento no piensa algo diferente en el predicado, sino que más bien redescubre en él al sujeto mismo" (23), resumen, mejor dicho asume Gadamer, puesto que su hermenéutica también apunta explícitamente a cuestionar la estructura 'S es $\mathrm{P}$ ', en sus consideraciones sobre la naturaleza especulativa

(23) Ibidem, p. 28. 
del lenguaje. Si observamos un ejemplo que ponga en evidencia el movimiento de la frase especulativa como 'lo real es lo universal', se nos dice no precisamente que sobre lo real se predica lo universal, sino que éste es la esencia misma de lo real (24).

Así se rechaza la idea de que el lenguaje filosófico pueda predicar algo sobre algo, ya que no se da en el terreno de la demostración sino a través del procedimiento dialéctico referido al automovimiento de los conceptos en progresión contínua. Hegel escribe: "La proposición debe expresar lo que es lo verdadero, pero ello es, esencialmente sujeto; y, en cuanto tal, es sólo el movimiento dialéctico, este proceso que se engendra a sí mismo, que se desarrolla y retorna a sí (...) una vez separada la dialéctica de la demostración, el concepto de la demostración filosófica se ha perdido, en realidad" (25).

Gadamer no acepta la orientación de la dialéctica hegeliana por el espíritu especulativo del lenguaje; opina que presenta una limitación en razón de que "sólo pretende extraer del lenguaje el juego reflexivo de sus determinaciones del pensamiento, y elevarlo por el camino de la mediación dialéctica dentro de la totalidad del saber sabido, hasta la auto-conciencia del concepto" (VM I:561).

La experiencia lingüística del mundo, tal como es postulada por la hermenéutica requiere una visión más amplia de lo especulativo en el lenguaje, que excede la prefiguración de las

(24) Walton, Roberto, véase Razón especulativa y relaciones internas en Escritos de Filosofía, Academia Nacional de Ciencias, Buenos Aires, 1980, p. $71 \mathrm{ss}$. El autor expoone en este ensayo algunas concepciones idealistas, relacionadas con el tema de la razón especulativa según Hegel, cuya lectura es recomendable aunque no refiera la vinculación entre la filosofía hegeliana y la hermenéutica filosófica en la temática de lo especulativo.

(25) Hegel, G.W.F., Fenomenología del Espiritu, México, FCE, 1985, p. 43. 
relaciones lógicas, una visión que abarque, además, la realización de un sentido, el acontecer del hablar y del comprender: "Esta realización es especulativa en cuanto que las posibilidades finitas de la palabra están asignadas al sentido de su referencia como a una orientación hacia el infinito" (VM I:561). Y más aún: si el lenguaje tiene un significado ontológico universal, se debe a su modo de ser especulativo, es decir, lo que adviene al lenguaje es distinto de la palabra, pero no dado con anterioridad al lenguaje, ya que en la palabra realiza su propia determinación, mientras que ésta es tal por lo que accede al lenguaje (VM I:cfr.568).

Si hablar es un comportamiento especulativo, esto se debe a que las palabras no son copia de una realidad extralingüística, expresan una relación con una totalidad que jamás es dicha. Esto acontece en el hablar cotidiano, pero se muestra de manera intensa en la poesía, donde lo que enuncia este enunciar especulativo no es el contenido de lo enunciado, sino -y sobre todo- una relación con el ser, con el horizonte que "representa el nuevo aspecto de un nuevo mundo en el medio imaginario de la invención poética" (VM I:563).

Como Heidegger, Gadamer nos invita a escuchar a los poetas, a instalarnos en la intimidad de la palabra donde advienen las cosas que son nombradas, donde el mundo es configurado por el lenguaje y éste por el mundo, de tal modo que entre el significado y el ser, LO que se dice y lo DICHO "no hay nin-guna corriente de aire que nos hiele" (26). Si el poeta aparece, en Hölderlin, como el mediador entre los dioses y los hombres, en Gadamer, el lenguaje es el mediador entre el hombre y las cosas. Si en Hölderlin el poeta se va transformando en el guardián de la huella que dejan los dioses en su huida, el her-

(26) Gadamer, H-G., Poema y Diálogo, p. 137. 
meneuta se mantendrá en el espacio dialéctico de la finitud lingüística que apunta, con máxima expectación, a la totalidad de su sentido.

En resumen: la dialéctica gadameriana está profundamente marcada por la obra platónica, pero su lectura es un antídoto contra los dualismos doctrinarios puesto que el mundo de las ideas y de las apariencias, del ser y del no ser, se dan inextricablemente unidos en el fenómeno del lenguaje.

Adviértase, por otra parte, la impronta de la dialéctica hegeliana en esta hermenéutica que, según nuestra lectura, afirma los aspectos especulativos del fenómeno lingüístico estudiados por Hegel, si bien trasciende la dimensión lógica, mostrándonos una concepción más abarcante que incluye otros comportamientos linguísticos y el universo del discurso poético.

En cuanto al legado de Heidegger está visiblemente expuesto en sus textos, así en lo que concierne a la superación de los conceptos canónicos de la metafísica, aunque los caminos de ambos pensadores se bifurcan: mientras Heidegger remonta hasta la filosofía presocrática en la búsqueda de una experiencia primigenia del ser, Gadamer permanece en el dominio del lenguaje coloquial sostenido por una dialéctica de pregunta y respuesta y de apertura infinita.

Pero advertimos, sobre todo, tenso el oído de este filósofo para oir la voz de los poetas: sus ensayos sobre Hölderlin, Stefan George, Rainer María Rilke, Paul Celan, entre tantos otros, le llevan a la convicción de que "...la lengua no es sólo la casa del ser, sino también la casa del ser humano, en la que vive, se instala, se encuentra consigo mismo, se encuentra con el Otro, y que la estancia más acogedora de esta casa es la estancia de la poesía, del arte (...). Recordarlo para uno mismo es 
la cuestión más intima de cada uno. Hacerlo para todos, y de manera convincente, es la misión de la filosofia" (27).

\section{Resumen}

El propósito de este ensayo consiste en una lectura de la hermenéutica filosófica (según Hans-Georg Gadamer) destacando los referentes históricos del pensamiento dialéctico (v.g. Platón, Hegel); distinguimos la aceptación de algunos elementos tradicionales respecto a la crítica ejercida sobre otros y la progresiva configuración de su hermenéutica como una dialéctica dialógica marcadamente original. Se observa el discurrir dialéctico en los diversos comportamientos lingüísticos (desde el enunciativo hasta el del universo poético).

(27) Gadamer, H-G., La herencia de Europa, Barcelona, Ed. Península, 1980 , p. 156. 